\title{
Fire Safety in Chemical Laboratories
}

\author{
Remi Parent*
}

\begin{abstract}
Fire safety in chemical laboratories is often the stepchild in industrial safety concepts. This is due to the small quantities of chemicals handled and underestimation of loss of research results and infrastructure. Managing fire safety in chemical laboratories depends more on prevention than the work of fire fighters. In this article the safety policy of Givaudan is described in detail.
\end{abstract}

Keywords: Chemical laboratories · Emergency response file - Employee training · Risk assessment · Safety concept

\section{Introduction}

Although companies recognise the strategic importance of addressing the fire risk in industrial laboratories, this is frequently overlooked when compared with the potential risks inherent in manufacturing activities. This is mainly because of the much greater quantities of chemicals that are generally handled on a production scale. Although few companies could effectively retain their market position if they lost their research and development or quality control facilities, laboratory personnel are not always made aware of this aspect of their remit.

Nevertheless, the risk of a fire is always present and constitutes by far the leading cause of serious losses in laboratories. In order to address this problem, it is therefore essential to pursue a policy of fire prevention coupled with appropriate and ongoing staff training.

\section{Potential Risks}

The obligatory first stage in implementing this policy consists of determining the potential risks specifically associated with laboratory operations.

${ }^{*}$ Correspondence: R. Parent

Safety and Environment Manager

Givaudan Suisse SA

Chemin de la Parfumerie 5

$\mathrm{CH}-1214$ Vernier

Tel.: +41227809111

Fax: +41227809150

E-Mail: remi.parent@givaudan.com

www.givaudan.com
Two main categories of risk become apparent from this preliminary analysis:

The dangers associated with chemicals stored at these locations:

- Flammable liquids and solids

- Chemical incompatibility between substances

- Combustive materials

- Peroxides

- Substances with spontaneous combustion tendencies

- Substances that give off a flammable gas on contact with water

- Flammable gases used as reagents and for instruments

- Incorrect labelling

- Use of substances that are inappropriate, have not been verified or have deteriorated

- Electrostatic discharge

Dangers due to the human factor:

- Boredom with routine, overconfidence, apathy

- Deviations from operating instructions

- Disregard for hygiene and safety regulations

- Poor use of laboratory space (bench, fume cupboard)

- Disregard for standard procedures

\section{Emergency Response Concept}

A second stage, equally necessary, consists of mitigating the potentially disastrous effects of a laboratory fire. Experience from catastrophic situations that have occurred in the past, at various sites, shows that the most effective response is nearly always that provided by the person who discovers the fire, because of his or her quick action.
To optimise the efficacy of an immediate response, it is essential that whoever takes action should be able to find the equipment needed without delay, in particular the extinguisher appropriate to the hazard to be combated. For this purpose it is common practice in laboratories to banish extinguishers intended for Class A fires (solid materials that do not melt, such as wood, paper, etc.), in favour of those suitable for Class B (liquids or solid materials that melt, liquid fuels, resins, etc.), Class $\mathrm{C}$ (gases) and Class D (metals, sodium, magnesium, etc.) fires, which are more likely in view of the substances that are actually present. This subject therefore requires much thought to be given to the choice of emergency response facilities suitable for laboratories. It is thus necessary to procure specific equipment, of an industrial type but of smaller dimensions, i.e. in sizes normally encountered in office buildings.

\section{Emergency Response File}

The third stage consists of drawing up emergency response plans that are just as rigorous as those assigned to the production plant.

We now take a look at the experience of Givaudan SA at Vernier, Switzerland. Following successive expansions of the site accompanied by an increase in the number of buildings, the emergency services felt the need to have help and support available other than that committed to memory, in the form of written documentation. Initially, the emergency response files consisted in effect of the architects' plans with the building numbers and an indication of the access and escape routes. The need for reliable and precise information at all times has resulted 

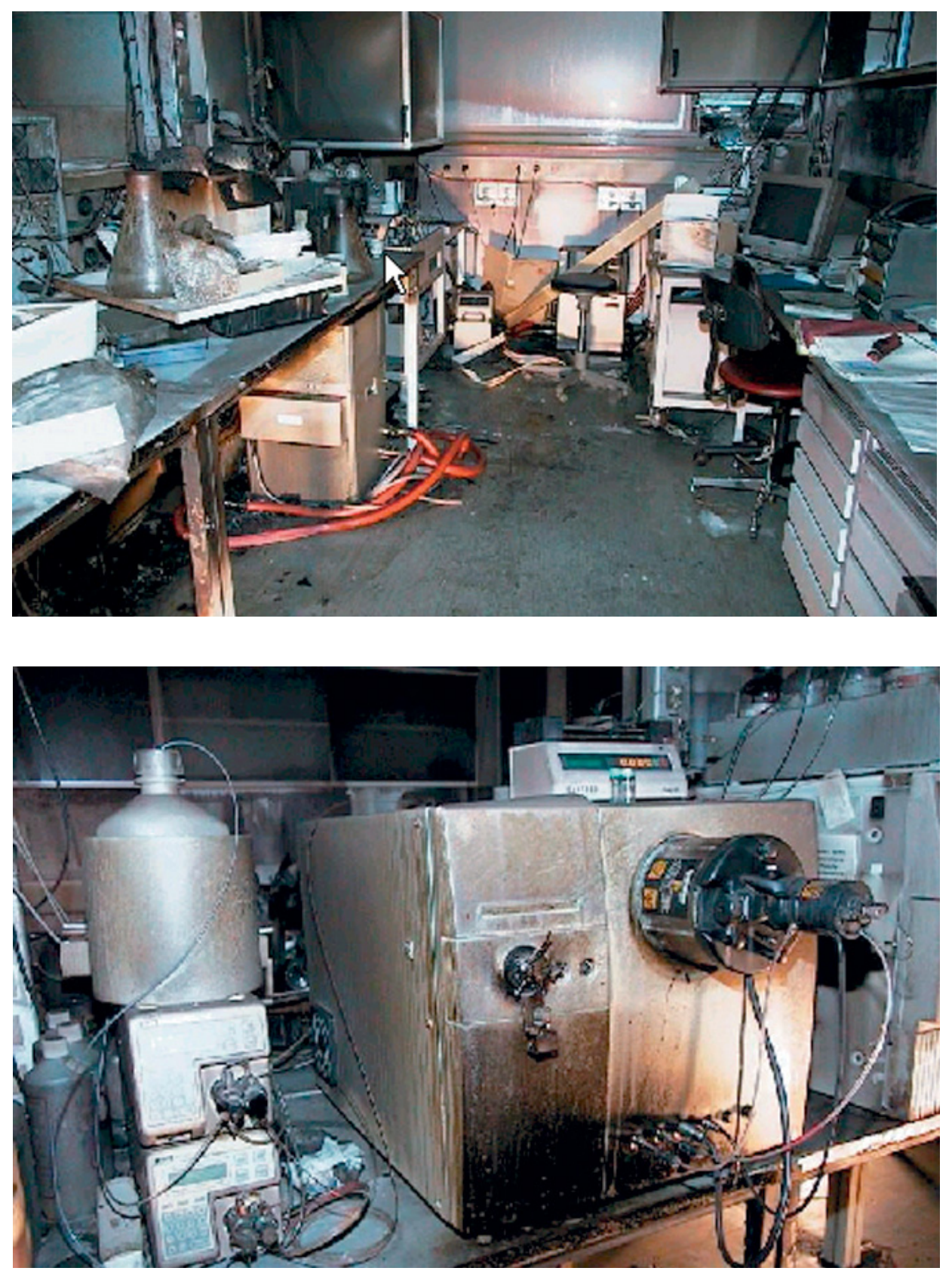

in this documentation evolving into what it is today, a complete working file for internal and external emergency response personnel. In addition, because of the very accurate information which it contains, it is also invaluable for training plant personnel.

Its standardised structure conforms to the following general layout:

\section{General section:}

- The situation of the site (area, capacity)

- A description of the company

- Its economic sector

- A description of its activities

- The number of personnel employed during the day and at night

- A schematic diagram of the company

- The job titles and names of company managers

- The means of contacting them

- An accurate description of the immediate environment
- Residential areas, schools and other industries within successive radii of $500 \mathrm{~m}, 500$ to $1000 \mathrm{~m}, 1000$ to 1500 $\mathrm{m}$, etc.

- The local topography, geology and hydrology

- Location of pillar and underground hydrants

- Firefighting equipment

- All the assembly points on the site

- A list of all conventional signs and notices

- 'Reflex action' instruction cards - FIRE - ACCIDENT - POLLUTION

- Fire safety and evacuation instructions

\section{Section specific to the building concerned:}

- Location and category of stored chemicals
Fig. 1. Heavy fire and smoke damage in research laboratories can result in considerable business loss due to delayed launch of new products
Fig. 2. Property damage by smoke impact on expensive LC-MS equipment

- Specific equipment

- Collateral risks

- Location of safety devices, emergency stop buttons, emergency showers, eye bath fountains and fire blankets

- Assembly points for building personnel

- Location of fire alarm control panels, extinguishers, axial-feed hose reels, smoke vents and other fire safety equipment

\section{Employee Training}

Management of the human factor is a fundamental element in any effective policy for fire prevention. The Vernier site has taken a number of steps to pursue this objective, every employee being made aware of safety matters as soon as he or she takes up employment. An ongoing safety orientation then continues for as long as an 
employee remains with the company.

This safety awareness strategy starts immediately when a new employee is welcomed, by issuing him or her with the company's safety booklet, in which general information is presented on essential subjects, in particular:

- Occupational hygiene

- Emergency response actions

- Fire precautions

- Environmental protection

The booklet also includes reminders in the form of a memory-jogging quiz:

- Where is the nearest manual call point?

- Where is the nearest appropriate extinguisher?

- Where is the nearest emergency shower?

- Where is the assembly point for the building personnel?

Plus the appropriate rules for employee action:

- How to make the installations safe

- How to prevent a chain reaction

- How to use the extinguishing equipment without taking any risks

Every two years the complete workforce of Givaudan at the Vernier site, together with the personnel employed in the field, receives practical instruction on the handling of extinguishers and their use for different classes of fire. This training is given by the company's professional fire brigade. In addition, fire drills are held regularly to practise evacuation of the buildings.

In the particular case of the laboratory personnel, a certain number of Good Laboratory Practice topics are regularly refreshed, particularly the following points:

- Not working at a cluttered laboratory bench

- Never using damaged glassware

- Storing only minimum quantities of chemicals

- Correctly labelling all containers

- Not permitting work to be carried out unsupervised

- Using fire-resistant safety cabinets

Additionally, nine times a year a safety awareness day is organised so as to cover the entire workforce. This day involves a small group of twenty or so employees coming together each time, and is more than just a simple information day, since it offers a real forum for constructive dialogues and exchange of ideas between all the employees on the site.

The company also has an internal emergency response structure comprising a unit of voluntary firefighters, some 60 employees normally employed in all sectors of the company. They take part in regular training sessions and drills carried out directly on equipment suitable for their emergency response function, in particular:

- A water tender

- Two appliances equipped with dry powder extinguishing systems, capacities $750 \mathrm{~kg}$ and $1000 \mathrm{~kg}$

- Six motor pumps

In conclusion, it is essential to remember that precautionary measures are always much more effective than those offered by emergency response facilities, even the most sophisticated ones - 'Prevention is better than cure'. An incident of any description is always the result of a multitude of seemingly insignificant causes, and it is only by carrying out a systematic analysis of all these anomalies, even those that appear to be trifling, that a company can truly claim to have significantly reduced its potential hazards.

Received: December 5, 2003 